\title{
O Privadismo do Direito Criminal na Doutrina de Teixeira de Freitas
}

\author{
Waldemar Ferreira
}

1. Muito invejou Teixeira de Freitas a fortuna de Antonro Luls de Seabra, quanto às criticas feitas ao projeto de codigo civil português, de sua autoria, a despeito de muitas não terem sido, nem em quantidade, nem em qualidade: O convite, feito pelo governo 'português, por portarias e ofícios, aos tribunais e instituições cientificas e universitarias, para que sobre o projeto se manifestassem, apresentando pareceres, emêndas ou aditamentos, deu, no sentir de LuIz da CunHA Gonçalves, "medíocre resultado, pois os poucos trabalhos que foram produzidos só se notabilizaram pela sua superficialidade, incluindo os dos professores da Faculdade de Direito de Coimbra, que eram membros da comissão revisora; de tal sorte que o ilustre autor do Projeto não đeu importância alguma às criticas feitas ao seu trabalho, antes replicou com azedume, mantendo os seus pontos de vista" (1).

Causaram elas, todavia, inveja ao genial jurisconsulto brasileiro.

(1) Luiz da Cunha Gonçalves, Tratado de Direito Civil em comentário ao Código Civil Português, vol. 1 (Coimbra, 1929), pag. 123, n. 20. 
"Os estudos juridicos", escreveu êle, "os estudos jurídicos são geralmente réputados como aridos e ingratos, os habitos da meditação não são muito vulgares; e na verdade assás afligem êsses golpes, que a meia sabedoria nunca dispensa. Bem afortunado foi o sr. SEABra, tendo por competidor um jurisconsulto provecto, a quem não falecem nem luzes nem experiência para aquilatar a sua obra. Quão diversa foi a nossa estrela! Publicado o primeiro fruto de nossas tenazes locubrações (falamos da Consolidação das Leis Civis), a sua única censura foi a mudez do silencio, quebrado apenas pelas vozes perdidas de dois artiguitos, que inseriu o Diário do Rio de Janeiro, onde se nos falou de uns direitos mistios que até hoje não conhecemos, e se nos disse que as leis deviam ser escritas em estilo bíblico. Se não fossemos de sobejo compensados 'pelo poderoso acolhimento do sábio Monarca, que aprovou nossos trabalhos, e por todos os modos entre nós alimenta o sagrado fogo da ciência; se não fôra tambem a outra preciosa recompensa de um doutissimo voto oficial que precedêra a essa aprovação soberana, talvez que tantas vigílias fôssem desde logo condenadas ao mais profundo esquecimento" $\left({ }^{2}\right)$.

(2) Augusto Teixeira de Freitas, Nova Apostila à censura do Senhor Alberto de Morais Carvalho sobre o Projeto do Código Civil Portugues (Rio de Janeiro, ed. Laemmert, 1859), pag. 8.

0 voto oficial consignou-se em parecer da comissão nomeada em 1858, pelo govêrno, composta dos Conselheiros ViscondE DE Uruguai, José Tomaz Nabuco de Araujo e Caetano Alberto Soares :

"Por meio de exame, a que procedeu a Comissão, chegou ela à justa apreciação dessa elaboração, que, a par do estudo profundo, erudição vasta, e método didático, dá testemunho do zelo, dedicação e constância do seu distinto autor; e recomenda e atesta sua habilitação para o Projeto do Código Civil, do qual a Consolidação é preparatorio importante.

“A Comissẫo considera a Consolidação digna de aprovação, senão de louvor do Governo Imperial, pela fidelidade e clareza do texto, pela ilustração das notas, as quais o fundamentam, e ao mesmo passo o regeneram dos êrros e abusos da praxe; sendo que destarte a Consolidação além do fim especial a que se destina, presta um serviço importante ao fôro, desvairado pela incerteza e diversidade de opiniôes, as quais, no vasio do direito pátrio, acham largas para o arbítrio, adotando muitas vezes como subsidiárias, por supósta omissão das nossas leis, disposições que lhe são contrárias. A Comissão conclúe que a Consolidação merece aprovação e louvor do Governo Imperial" 
2. Escritas se achavam palavras tais e, provavelmente impressas, quando Texixeira de Freitas se viu na necessidade de aditar ao volume, em que elas ganharam letras de fôrma, "satisfação em tempo".

"Era justa", disse êle, "era justa nossa mágua, ressentindo-nos da frieza dos tempos para com os estudos sérios, e trabalhos científicos; e saiba-se, que nem ao menos correspondidos fomos (houveram exceções) em cartas dirigidas a pessôas, que passam por Papinianos, mas de ciência guardada, só atestada por discipulos que adoram seu mestre, e juram em suas palavras. Felizmente ainda existem corações nobres, que sentem as pulsações do amor por tudo que é grande, e glorioso 'para a patria. Depois de escrevermos o que se lê na página $9 .^{\circ}$, um ilustrado jurisconsulto - o sr. Antonio Pereira Rebouģas, que já particularmente nos havia dado uma prova de aprêço aos nossos trabalhos, encetára no Correio Mercantil a publicação de várias censuras ao dispositivo de alguns Artigos da Consolidação das Leis Civis, e ilustrações de suas Notas. Cordialnente agradecemos ao nosso distinto Colega este tão louvavel expediente. Todos os seus judiciosos reparos serão cuidadosamente tomados em consideração, ou em artígos destacados e pelo mesmo jornal, ou em observações adicionais de uma 2. edição, para a qual já estamos autorisados pelo Govêrno. Provavelmente devem haver alguns pontos em que concordemos, e nós mesmos já temos uma bôa coleção de apontamentos para algumas retificações, que o tempo e a prática demonstram. Bem dificil é tomar um a um todos os mínimos traços de uma cópia em miniatura, que melhor com'paração não póde ter a simplificação e consolidação de materias esparsas por um sem número de átos legislativos. 0 trabalho é obrigado, e por demais acanhado - sermocinatur e vinculis. Já é tempo de não serem as causas precedidas pelos efeitos, de não ser a sabedoria um atributo suposto, uma centêlha de prestígio. Muito feliz fôra o Brasil, outro es'petáculo apresentaria a sua administração de justiça, se êle contasse muitos homens 
virtuosos e patriotas, como é o ilustre Jurisconsulto, a quem prestamos esta homenagem".

3. O extraordinário mérito da óbra de TexxeIra DE Freitas constituiu, sem dúvida, o seu maior defeito. Se a Consolidação das Leis Civis não provocou o movimento de opinião, que seu aparecimento justificava, aconteceu isso de estar o jurisconsulto, que a concebeu e realizou, muito acima da cultura jurídica do país, a despeito dos grandes e altos espiritos, que o conduziam nos seus destinos históricos. Achava-se, desde 1830, em execução o código criminal e, desde 1850, o código comercial, incontestavelmente dois grandes monumentos de sabedoria jurídica, que as leis de organização judiciária e 'processuais completaram, marcando as épocas em que se promulgaram. Não quis Teixeira de Freitas, como é de moda nos tempos atuais, preparar de afogadilho o projeto de código civil, de cuja redação estava incumbido. Se a Consolidação das Leis Civis foi o trabalho de sapa de sua construção, no Esboço lançaram-se os alicerces formidaveis em que êles assentariam e de cujo material se serviria Velez SARsfield para o lineamento do código civil argentino. Teve êste, por isso, de retorquir às criticas amargas e injustificaveis de Alberdr. "Mas", defendeu-se o codificador argentino, "mas el doctor Alberdr ha creido citarme ejemplos del código francés que equivocadamente cree que ha seguido el método de la Instituta y se burla de la preferencia que he dado al señor FreItas sobre Tronchet, Portalis, Maleville. El doctor Alberdi confiesa que no conoce los trabajos de la legislación del senor Freitas y parece convencido que nada mejor puede haber que los jurisconsultos que formaron el código francés, tan criticados hoy por los jurisconsultos de la misma nacion. Puede perdonarme que yo despues de un sério estudio de los trabajos del señor FrEITAs los estime sólo comparables con los de Savigny"

(3) Enrique Martinez Paz, Freitas y su influencia sobre el Código Civil Argentino (Cordoba, 1927), pag. LVI. 
Além das inúmeras concepções originais, que assinalaram o trabalho formidavel de Teixeira dE Freitas, sôbrepairou o principio mestre e original da unificação do direito privado, que propuzera ao Govêrno Imperial, em 1867, antecipando-se ao movimento legislativo que, dando desenvolvimento ao dispositivo constitucional de 1874, da Suiça, ensejou a unificação de consideravel parte do direito privado no código federal das obrigações de 1881. A despeito de aceito o 'plano unificador do direito privado brasileiro, em fórmula inteiramente original, pela Secção de Justiça do Consêlho de Estado, recusoul-o o Govêrno Imperial. A sua recusa envolveu o próprio Esboço. Deu o aviso de 18 de novembro de 1872 como rescindindo o contrato celebrado com Teixeira de Freitas, “já pelo tempo decorrido, já porque v. s. declarou, na sua mencionada representação, que, 'pela desharmonia profunda entre o seu pensamento e as vistas do Govêrno Imperial, julga-se inhabilitado para redigir aquêle projeto". Este participio havia de ter magoado sobremodo o jurisconsulto maior.

Não se julgara êle, com efeito, inhabilitado, mas incompatibilizado para a consecução do objetivo, em razão de se lhe ter a'presentado diretriz diversa. O plano de elaborarem-se dois códigos, um geral e outro especial, houve-o o ministro da Justiça, e era José de Alencar, do ponto de vista legislativo, como "frutos muito prematuros", embóra, do ponto de vista científico, revelassem "as altas faculdades do autor, e sua opulenta cultura jurídica" $\left({ }^{4}\right)$.

"O Govêrno", é da representação de Teixeira de Freitas; "o Govêrno espera por um projeto do código civil no sistema dêsse $E s b o ̂ c ̧ o$, sistêma traçado no meu contrato de 10 de janeiro de 1859, e para mim não há possibilidade de observar tal sistêma, convencido, como estou, de que a emprêsa quer diverso modo de execução. O Govêrno quer um projeto de código civil, para reger como subsidio ao complemento de um código de comércio; intenta conservar o código co-

(4) Waldemar Ferreira, Tratado de Direito Mercantil Brasileiro, vol. 1 (São Paulo, 1934), pag. 59, n. 21. 
mercial existente com a revisão, que lhe destina; e hoje minhas idéias são outras, resistem invencivelmente a essa calamitosa duplicação de leis civís, não distinguem no todo das leis desta classe algum ramo, que exija um código do comércio. O Govêrno só pretende de mim a redação de um projeto de código civil, e eu não posso dar êsse código, ainda mesmo compreendendo o que se chama direito comercial, sem começar 'por um outro código, que domíne a legislação inteira".

"Se", concluiu, "se me negam a possibilidade moral de arranjar códigos de rotina, que só servem para atrair recompênsas exteriores, então sou réu confesso".

Levou a lealdade do jurisconsulto, externando a divergência de seu pensamento e o ponto de vista governamental, em documento cuja valía se aparêlha com o ólvido, que sôbre êle caíu; levou-a a abandonar, cheio de amarguras, antes do remate, obra monumental, que, se não se condensou, naquêle tempo, nos articulados do código civil brasileiro, inspirou e reproduziu-se em bôa parte do código civil argentino, mercê do nobre e alto espirito de universalização, que a orientou.

\section{II}

Se, em Portugal, o projeto de código civil, elaborado por Antonio Luis de Seábra, teve crítica assás resumida, muito repercutiu no Brasil. Tanto que publicada a sua primeira parte, analisou-a Alberto de Morats Carvalho, em volume que iniciou notavel polêmica com o autor do projeto, e culminou com a entrada de Teixeira de Freitas no debate. Três apostilas tinha publicado aquêle $\left(^{5}\right)$, quando êste publicou a - Nova Apostila à censura do Senhor Alberto de Morais Carvalho sôbre o projeto do Código Civil Português.

(5) A polêmica se movimentou em vários volúmes, a saber: Alberto Antonio de Morais Carvalho, Observaçóes sôbre a primeira parte do projeto do Código Civil Português do Exmo. ConseIheiro Antonio Luis de Seábra. Lisboa, Imprensa Nacional, 1857. 
Do merecimento da crítica dos dois jurisconsultos brasileiros, falou, insuspeitamente, LuIz da CunHA Gonçalves, em mais de um passo. Apesar, disse êle, "apesar da calorosa defêsa que fica exposta, o plano do nosso código civil é, sem dúvida alguma, extremamente def eituoso, técnicamente inferior ao propugnado pelo jurisconsulto brasileiro TerxeIRA dE Freitas - a êsse tempo encarregado pelo govêrno brasileiro de elaborar também um projeto de código civil, e que, além dum titulo prielimiziar, em que se propunha tratar do lugar e do tempo, estabelecia uma parte geral em que se ocupava dos elementos do direito: pessoas - cousas atos juridicos, e uma parte iespecial, assim dividida: dos dos direitos reais, dos direitos pessoais, disposições comuns dos direitos reais e pessoais, incluindo nesta terceira parte as sucessões, o concurso de credores, a prescrição".

Mas, adiante escreveu, "se o direito civil é o complexo de todas as disposições que regem as relações civis dos individuos entre si (e também entre os individuos e o Estado), relações que correspondem aos direitos que as man-

Antonio Luis de Seára, Apostila ( $\left.n^{\circ} 1\right)$ à censura do sr. Alberto de Morais Carvalho sôbre a primeira parte do projeto do código civil. Coimbra, Imprensa da Universidade, 1858.

alberto Antonio de Morais Carvalho, Resposta à primeira apostila do senhor Antonio Luis de Seabra. Lisboa, Imprensa Nacional, 1858.

Antonio Luis de SEÁbra, Apostila (n.o 2) à censura do sr. Alberto de Morais Carvalho sôbre a primeira parte do código civil. Coimbra, Imprensa da Universidade, 1858.

Alberto ANTONio de Morais Carvalfo, Resposta à segunda apostila do senhor Antonio Luiz de Seábra. Lisboa, Imprensa Nacional, 1858.

Antonio Luis de Seábra, Apostila ( $\left.n .^{\circ} 3\right)$ à censura do sr. Alberto Morais de Carvalho sóbre a primeira parte do projeto do código civil. Coímbra, Imprensa da Universidade, 1859.

Alberto Antonio de Morais Carvalho, Resposta à terceira apostila do Senhor Antonio Luis de Seábra. Lisboa, Imprensa Nacional, 1859.

Augusto Teixeira de Freitas, Nova apostila à censura do senhor Alberto de Morais Carvalho sobre o Projeto do Código Civil português. Rio de Janeiro, Tipografia Universal de Laemmert, Rua dos Inválidos, 613, 1859.

ANTanio Luis DE SEÁbra, Novissima Apostila em resposta à diatribe do sr. Augusto Teixeira de Freitas contra o Projeto do Código civil português. Coimbra, Imprensa da Universidade, 1859. 
têm, o ilustre Seabra deveria, como lhe observara TeIXeIra de FreITAS, classificar essas relações e direitos, e não dissecar os elementos do direito em geral, para fundar num dêles isoladamente o seu sistêma, erigindo assim um edifício, não numa base inteiriça, mas sim numa base mutilada" $\left({ }^{6}\right)$.

Poder-se-ia, realmente, acompanhar a argumentação de Teixeira de Freitas e estudar, de acôrdo com ela, o código civil português, se apenas não nos interessasse um dos aspectos de sua critica, vigorosa e profunda.

Não era menor que o jurista o polemista.

\section{III}

5. "Não pensamos", doutrinou o jurisconsulto brasileiro, "não pensamos que o nobre redator do projeto esteja perssuadido, com a mór parte dos escritores franceses, de que o direito criminal seja um ramo do direito público. Se o passado do seu direito pátrio, se os Estatutos da Universidade de Coimbra de alta sabedoria, sicut cymba in oceano; se a velha distinção entre crimes públicos e particulares, distinção ainda guardada na Refórma Judiciária de 1841, posto que omitida na posterior legislação do código penal; se ainda não se tem desquitado das naçōes tradicionais de um direito privado - quod ad singulorum utilitatem pertinet, e de um direito civil - quod quisque populus ipse sibi constituit; abandone agora essas suposições falazes, que se têm perpetuado a mercê do som das palavras, mas que não acham lugar em qualquer espirito que distingue e firma idéias sem lhe importar a roupagem dos vocábulos".

"Se o direito criminal não entra na esféra do direito público, é bem claro que não póde ser outra cousa senão um ramo do direito privado. Se tanto nos quizerem conceder, e uma vez que não se recuse tambem a distinção en-

(6) Luiz da Cunha Gongalves, Tratado de Direito Civil em comentária ao Código Civil Português, vol. 1 (Coimbra, 1929), pag. $117,{ }^{\circ} 19$. 
tre crimes públicos e crimes particulares, ao menos sernos-á permitido concluir logicamente que êsses crimes particulares entram na órbita do direito privado, e que portanto o direito privado compreende alguma cousa mais do que as regras ou disposições do direito civil propriamente dito".

"Na peior das hipóteses, não deixaremos de reconhecer as bôas consequências práticas dessa divisão das leis, que distingue os direitos que são do interêsse público daquêles que são do méro interêsse privado - unicuique licet contemnere haec quae pro se introduta sunt; porém ao mesmo tempo diremos que uma tal distinção, tão aproveitavel no ponto de vista das faculdades jurídicas, é falsa e funesta em relação do direito como sinônimo de complexo de leis".

"Ela conduz a uma eterna impossbilidade de traçar a linha divisória entre o direito público e o direito privado, impossibilidade em que laboram todos ou quasi todos os escritores francêses e alemãis; bem que em seus escritos não deixem de entrever a idéia carateristica, que só nos póde dar a base para uma precisa separação.

"E na verdade, a persistir-se em tal ponto de vista, o direito civil será reduzido a um circuito mesquinho; pertencendo ao direito público uma grande parte de suas disposições, e ficando o pouco que lhe restar travado assim mesmo de uma mescla, que nem ao mais penetrante classificador consentirá livrar-se de uma perplexidade contínua. Eis a razão do irresoluvel problema por efeito da mesma natureza complexa do direito".

6. Lida nos dias de hoje, essa curiosissima passagem causa móssa ainda aos espíritos menos perspicazes. A divisão dos crimes em públicos e particulares e a inclusão do direito criminal na esfera do direito civil, que regula os direitos e obrigações de órdem privada concernentes às pessoas, aos bens e suas relações, aturdem o leitor desprevenido, vindo o conceito de onde veiu. Obriga-o, em seguida, a meditar, a firmeza da asserção, a reclamar outras e 
mais profundas indagações. Não teria sido TeIXeIra DE Freitas levado a ela pelo calor da polêmica?

A resposta negativa logo se apresenta, dada a circunstância de ter êle reproduzido pensamento antigo e, portanto, persistente, resultado de convencimento.

7. “A divisão de todas as leis (dizemos nós em um outro trabalho, que nos foi incumbido pelo Govêrno Imperial, e que já se acha nos prelos) derivada da distinção e diferença das relações jurídicas das duas personalidades, que funcionam na vida inteligente, é uma divisão real fundada na natureza das cousas.

"Ela é perfeita, e confirmada pela análise de todas as leis; porque fóra dessas duas categorias não existe ef etivamente lei alguma. Ela é perfeita, e racionalmente exata; porque o concurso de personalidades individuais, e de uma personalidade pública, não póde dar em resultado, senão ou relações entre aquela, ou relações com esta.

"Em toda a escala de suas manifestações, a personalidade pública mostra-se como poder simplesmente constituido, como poder constituido e organizado, como poder em ação efetiva; e finalmente desce à arêna dos individuos, individualiza-se a par dêles e coloca-se no mesmo pé, submetendo-se às mesmas aplicações das leis pelo poder judicial, e provocando como indivíduo a ação especial dêste poder. Eis a última personificação, que toma o poder público, personificação que equivale a uma transformação completa, e o despe de seu caráter de soberania. Mas aí, nêste grau extremo da escala, termina a esféra do direito público, e começa a do direito privado".

"Assim apreciado o poder público, quando, representado pelos agentes de seu ministério, vem solicitar justiça aos magistrados e tribunais, como se fôra um simples particular, acha-se a idéia carateristica, que nos fornece a base de uma exata linha de separação entre o direito público e o direito privado. Partindo-se de uma distinção nêste aspecto, todas as relações protegidas e reguladas pe- 
lo direito criminal vêm necessariamente arranjar-se na esféra do direito privado; e consequentemente é de mister separar todos os direitos inerentes a essas relações, para não envolvê-los, ou reproduzí-los inutilmente, nas prescrições do direito civil. Separado e conhecido o que tem sido objeto da legislação penal, todo o resto (no terreno do direito privado) é o que pertence ao direito civil propriamente dito, é o que verdadeiramente constitue a matéria própria de um código civil. E qual o limite racional entre o civil e o penal?"

“As relações jurídicas dos cidadãos entre sí (escusado é dizer privadas, pois não há outras dos cidadãos entre sí que tenham o nome de públicas) correspondem a uma parte dêsses direitos, que em sua variada frase a Carta Portuguêsa denomina indlividuais ou civis; mas, assim como dêsses direitos individuais alguns há que não são da alçada do direito privado por entrarem na esféra do direito administrativo, outros há que são os propriamente civis, por isso mesmo que são os únicos que o código civil regula e protege, e que racionalmente só deve abranger.

"Ora, todos os direitos individuais, ou são absolutos, ou são relativos; não há espécie alguma de direitos, que não cáia debaixo dessa divisão ampla e dominante. Os primeiros são os originários da personalidade do homem, e os hipotéticos da propriedade; os segundos são os que recáem sôbre pessoas certas e determinadas. Pois bem: quanto aos primeiros, entram todos na compreensão do direito criminal que os protege com a penalidade, e só o de propriedade entra na órbita do direito civil; quanto aos segundos, excetuados alguns casos especiais, pertencem em regra ao direito civil".

8. Desenvolvendo essa argumentação, acrescentou TEIxeira de Freitas em nota:

"Tudo o que se acha no projeto, arts. 2.634 a 2.670, sôbre a - responsabilidade civil em geral, sôbre a - responsabilidade civil conexa com a responsabilidade criminal, 
sôbre a - responsabilidade meramente civil, confirma exatamente nossos assertos, em acôrdo com uma Not. da Consolid. das Leis Civ. Introduc. pág. 45". A responsabilidade civil conexa com a criminal (art. 2.641) diz respeito à ofensa dos direitos primitivos e à dos direitos adquiridos (propriedade em geral), reprimidas no direito criminal. $A$ responsabilidade meramente civil, resultante da inexecução dos contratos, e de quaisquer outras obrigações (direitos relativos - pessoais), regula-se unicamente pelo direito civil. Como ainda mesmo errando-se, brilha a verdade!" (7).

Esclarece esta nota, realmente, o ponto de vista de Teixeira de Freitas. Consignando, ademais, as noções fundamentais, na Introdução da Consolidação das Leis Civis, assentou êle dois principios:

a) "a distinção das personalidades, e sua razão de existência, assinalam os limites do direito público e do direito privado";

b) "a sanção da pena no direito privado extrema as leis criminais das leis civis".

Tendo estabelecido a divisão dos direitos em pessoais e em reais, fazendo classificação, que é o ponto de partida do sistema, que esboçou, chegou êle aos seguintes corolários :

"Os chamados direitos absolutos - liberdade, segurança e propriedadie - entram na compreensão da legislação criminal, que os protege e assegura com a penalidade. Dêsses direitos o de propriedade entra na legislação civil. $\mathrm{E}^{\prime}$ no direito de propriedade que havemos de achar os direitos reais.

"Os direitos pessoais, excetuados os poderes da personalidade pública no círculo das leis orgânicas e administrativas, de que agora não tratamos, pertencem em regra à

(7) Augusto Terxeira de Freitas, Nova Apostilla à censura do Senhor Alberto de Morais Carvalho sôbre o Projeto do Código Civil Português (Rio, 1859), pag. 14. 
legislação civil, que define e regula as obrigações dos indivíduos entre sí. Eis os nossos direitos pessoais" ${ }^{8}$ ).

9. Feita a bipartida divisão dos direitos, em tais termos, é ver como influiu ela na delimitação do ambito do direito civil do criminal.

Páginas adiante focalizou o jurisconsulto êsse ponto.

"A violação", eis como êle se exprimiu, "a violação de quasi todos os direitos pessoais, que fazem parte do nosso patrimônio, só dão lugar a ações civis, e não a ações criminais. Essa violação só póde partir da pessôa individualmente obrigada. Quanto à outra parte da propriedade, a violação produz quasi sempre ações civis. Quando produz ações criminais, a sanção não é completa com a aplicação da pena, falta a restituição da cousa, ou a indezação do dano, o que consegue-se por ações civis. Estes efeitos dimanam da natureza das cousas, já que nos delitos contra a propriedade corpórea necessariamente o objeto corpóreo está entre o agente, e o paciente, do delito; entretanto que a sanção penal é estranha ao destino dêsse objeto, afetando só a pessôa. Ao contrário, nos delitos contra a personalidade, não há nada de permêio entre o agente e o paciente do delito. Nestes delitos a ação imputavel, que os constitue, só póde ser atribuida a uma intenção malevola; ao passo que os direitos de propriedade podem ser violados por ignorância, por simples êrro. A sanção dos delitos contra a personalidade - contra os direitos de liberdade e segurança, fica preenchida em muitos casos com a aplicação de pena somente. Quando não ficar preenchida, por haver dano resultante, cuja reparação é necessária, a legislação tem providenciado para a satisfação dêsse dano. Resulta, pois, que os direitos de personalidade entram na legislação civil, tanto quanto se faz preciso que entrem, segundo os princípios".

E prosseguiu:

(8) Augusto Teixeira de Freitas, Consolidação das Leis Civis, ed. Garnier, 1, 1..$^{\circ}$ vol., pgs. LXII e LXVI. 
"Não haja' distinção entre as relações jurídicas, já do poder público, já dos indivíduos entre si; não haja distinção entre os direitos da personalidade, e os da propriedade, não se restrinja também a significação da palavra delito; e será impossivel marcar a linha' de separação entre o direito civil, e o direito criminal. Se no sentido mais filosófico os direitos da personalidade forem considerados de propriedade, seguir-se-á fazê-los entrar na órbita da legislação civil. A palavra delito é tomada em sentido tão largo, que Bentham, por exemplo, cujos escritos abundam em idéias tão luminosas, entendeu que toda a legislação civil rolava sôbre delitos, direitos, obrigações, serviços, noções congênitas. Em seu ensaio para distinção do penal e do civil, a mesma idéia ampla do delito induziu a reputar a lei penal uma consequência, continuação, e terminação da lei civil".

Passos adiante, positivou a doutrina:

“Tinhamos já notado, que sem restringir-se a significação da palavra delito não seria' possivel traçar a linha de separação entre o direito civil, e o criminal. Fixemos agora esta noção:

"1. $0^{\circ}$ - significação da palavra delito - toda a violação de direitos;

" $2 .^{\circ}$ - significação - toda a violação de direitos com intenção malévola;

“3.” - significação - toda' a violação de direitos com intenção malévola, reprimida pelas leis penais;

"4. - significação - toda a violação de direitos com intenção malévola, reprimida pelas leis penais correcionais.

"Esta última significação é alheia do nosso direito e da teoria da ciência; pertence toda ao direito francês.

“A primeira accepção é amplissima. Confrontada com as duas, que se seguem em escala descendente, serve para no direito civil extremar as obrigações ex-delicto de todas as outras obrigações dos contratos e quasi-contratos. As 
outras duas accepções separam o direito civil do direito criminal.

"O direito civil trata somente do delito pelo lado da reparação do dano causado, ou o delito seja reprimido pela legislação penal, ou não seja. Se há uma pena decretada pela lei penal, o delito é de direito criminal" ( $\left.{ }^{9}\right)$.

10. Tem-se, ao cabo desta digressão, indemonstrada a tése de constituir o direito criminal ramo do direito privado e não do direito público, em que se encontra situado. No emaranhado das relações êntre os homens quem, por ação ou omissão voluntária, negligência ou imprudência, viola direito, ou causa prejuizo a outrem, fica obrigado a reparar o dano. A mais não é coagido do que a restaurar o direito violado ou a reintegrar o patrimônio desfalcado, no tanto quanto baste para a restituição dêste ao seu estado anterior. Do delito, portanto, nascem obrigações e direitos de órdem civil. Não se inscreve, por isso, o direito criminal no quadro do direito privado.

11. Para a tése de Teixeirat de Freitas poderiam ter contribuido, o código criminal de 1830 , de um lado a dividir os crimes em públicos e em particulares, afim de dar às vitimas dêstes ação penal; de outro, a prescrever as nórmas atinentes à satisfação do dano; e certos principios doutrinários, ainda não de todo esmaecidos.

$\mathrm{Na}$ ausência de lei civil, reguladora da reparação do dano advindo do delito, o código criminal alçou o preceito geral de o delinquente satisfazer o dano com o delito causado. A satisfação seria, pela sua letra, a mais completa, que fosse possivel, sendo, no caso de dúvida, a favor do ofendido. Para êsse fim, o mal, que resultasse à pessôa, e bens deste, seriam avaliados "em todas as suas partes, e consequências". No caso de restituição, far-se-ia a da própria cousa, "com indenização dos deterioramentos", e, na falta dela, de seu equivalente. Se se encontrasse a pró-

(9) Augusto Teixeira de Freitas, Consolidação das Leis Civis, ed. Garnier, vol. 1, Introdução, pags. CIV, CLXI. 
pria cousa em poder de terceiro, seria êle obrigado a entregá-la, havendo indenização pelos bens do delinquente. A avaliação do equivalente seria pelo seu preço ordinário, e pelo de afeição, contanto que êste não excedesse daquêle. Contar-se-iam juros, não apenas os ordinários, na proporção do dano e desde o momento do crime, mas também os juros compostos. A pluralidade de delinquentes acarretaria a obrigação solidária destes, dela não escapando os participantes gratuitos do produto do crime, até à concurrente quantia. A obrigação de satisfazer dano passaria aos herdeiros dos delinquentes e o direito de havê-la aos dos ofendidos. Em todo o caso, não tendo o delinquente meios para a satisfação, seria condenado a prisão com trabalho, pelo tempo necessário para o ganho da quantia necessária.

Ademais, a doutrina de Teixeira de Freitas, apareceu, também, no seio da escola criminal positiva, renovada por Thomsen, como observou Eugenio Florian. Pareceu a êste inaceitável a confusão, entre os sequazes dela feita, articulando o sistêma dos meios reparadores (direito civil), e dos meios repressivos e eliminatórios (direito penal), por diferir o direito penal do civil, profundamente, no objeto a nos meios, ar despeito da identidade do escôpo de um e de outro na tutela do direito ou seja na reação contra os atos antijuridicos $\left({ }^{10}\right)$.

12. Não pôs em circulação o notável jurisconsulto brasileiro, portanto, doutrina em prol da qual militasse apenas sua própria autoridade. Outros a defenderam. Incompativel é ela com as idéias modernas, de constante publicização do direito privado.

Sirvam as páginas, que aqui se encerram, para despertar maior e mais atilada indagação, no estudo da obra genial de Teixeirat de Freitas. Muito há nela a meditar e muitissimo a aprender.

São Paulo, 12 de janeiro de 1941.

(10) Eugenio Florian, Trattato di Diritto Penale, vol. I, parte 1. ${ }^{\mathrm{a}}$ - Dei Reati e delle Pene in generale, ed. Vallardi, 2. ${ }^{\mathrm{a}}$ ed., pag. $110, \mathrm{n}^{\circ} 59$. 